\title{
ASYMPTOTIC BEHAVIOR AND NONOSCILLATION OF VOLTERRA INTEGRAL EQUATIONS AND FUNCTIONAL DIFFERENTIAL EQUATIONS ${ }^{1}$
}

\author{
A. F. IZÉ AND A. A. FREIRIA
}

ABSTRACT. It is proved that if $q_{i j}(t, s) \rho_{j}(s)\left[\rho_{i}(t)\right]^{-1}$ is bounded, $i, j$ $=1,2, \ldots, n$, and $f(t, x, x(u(s)))$ is "small",

$$
x(u(s))=\left(x_{1}\left(u_{1}(s)\right), x_{2}\left(u_{2}(s)\right), \ldots, x_{n}\left(u_{n}(s)\right)\right)
$$

with $u_{i}(t) \leq t$ and $\lim _{t \rightarrow \infty} u_{i}(t)=\infty$, the solutions of the integral equation

$$
x(t)=h(t)+\int_{0}^{t} q(t, s) f(s, x(s), x(u(s))) d s
$$

satisfy the conditions $x(t)=h(t)+\rho(t) a(t), \lim _{t \rightarrow \infty} a(t)=$ constant where $\rho(t)$ is a nonsingular diagonal matrix chosen in such a way that $\rho^{-1}(t) h(t)$ is bounded. The results contain, in particular, some results on the asymptotic behavior, stability and existence of nonoscillatory solutions of functional differential equations.

Consider the system of Volterra integral equations

$$
x(t)=h(t)+\int_{0}^{t} q(t, s) f(s, x(s), x(u(s))) d s+\int_{0}^{t} q(t, s) g(s) d s
$$

where $h=\left(h_{1}, h_{2}, \ldots, h_{n}\right), f=\left(f_{1}, f_{2}, \ldots, f_{n}\right), g=\left(g_{1}, g_{2}, \ldots, g_{n}\right)$ are column vectors in $E^{n}, q=\left(q_{i j}\right)$ is a $n \times n$ matrix in Euclidean $n$-dimensional space, $x(t)=\left(x_{1}(t), \ldots, x_{n}(t)\right), x(u(t))=\left(x_{1}\left(u_{1}(t)\right), x_{2}\left(u_{2}(t)\right), \ldots, x_{n}\left(u_{n}(t)\right)\right)$, $u_{i}(t)$ continuous, $u_{i}(t) \leq t, t \geq 0, \lim _{t \rightarrow \infty} u_{i}(t)=\infty, i=1,2, \ldots, n$.

We show here that the results obtained in [2] are also true for equation (1) which is more realistic physically; furthermore some mathematical models arising in biology are described by equations of type (1) and, in particular, by retarded differential equations.

We assume the hypotheses:

$\left(\mathrm{H}_{1}\right)|q(t)|$ and $|g(t)| \in L(0, c), 0<c<\infty$,

$\left(\mathrm{H}_{2}\right) h(t)$ is continuous for $0 \leq t<\infty$,

$\left(\mathrm{H}_{3}\right) f \in C\left([0, \infty) \times E^{n} \times E^{n}, E^{n}\right), E^{n}=R^{n}$ or $C^{n}$.

These conditions guarantee the local existence of continuous solutions and continuability of each solution so long as they remain bounded; the proofs,

Received by the editors December 4, 1973 and, in revised form, June 25, 1974. AMS (MOS) subject classifications (1970). Primary 45D05; Secondary 34K xx.

Key words and phrases. Volterra integral equations, asymptotic properties, almost all, kernel, asymptotic behavior, uniform stability, uniform asymptotic stability, nonoscillation, functional differential equation globally bounded.

1 This research was completed under partial support of FAPESP, CAPES and CNP q, Brasil. 
as well as the proofs of Lemma 2 in [2], are the same, with small changes, given in [7] or [8].

We assume the hypotheses:

$$
\begin{aligned}
& \left|f_{i}(t, x, y)\right| \leq \sum_{i=1}^{n} \epsilon_{i j}(t)\left|x_{j}\right|^{p}+\sum_{j=1}^{n} \epsilon_{i j}^{\prime}(t)\left|y_{j}\right|^{q}, \\
& \epsilon_{i j} \geq 0, \quad \epsilon_{i j}^{\prime} \geq 0, \quad p_{j}, q_{j}>0, \quad i, j=1,2, \ldots, n,
\end{aligned}
$$

$$
|x|<H, \quad|y|<H, \quad H \leq \infty
$$

$\int^{\infty} \epsilon_{i j}(t)\left|\rho_{j}(t)\right|^{p} j\left|\rho_{i}(t)\right|^{-1} d t<\infty, \quad\left|\rho_{i}(t)\right|>0, \quad i, j=1,2, \ldots, n$,

$$
\int^{\infty} \epsilon_{i j}^{\prime}(t)\left|\rho_{j}\left(u_{j}\right)\right|^{q}\left|\rho_{i}(t)\right|^{-1} d t<\infty
$$

$\left(\mathrm{H}_{5}\right) \int^{\infty}\left|g_{i}(t)\right|\left|\rho_{i}(t)\right|^{-1} d t<\infty$,

$\left(\mathrm{H}_{6}\right) q_{i j}(t, s) \rho_{j}(s)\left[\rho_{i}(t)\right]^{-1}$ are bounded for $0 \leq s \leq t<\infty, i, j=1,2$, $\ldots, n$.

$\left(\mathrm{H}_{6}^{\prime}\right)\left(\mathrm{H}_{6}\right)$ is satisfied and $\lim _{t \rightarrow \infty} q_{i j}(t, s)\left[\rho_{i}(t)\right]^{-1}$ exists for almost all values of $s$.

Theorem 1. Assume, with respect to equation (1), $\left(\mathrm{H}_{4}\right),\left(\mathrm{H}_{5}\right)$ and $\left(\mathrm{H}_{6}\right)$ and let $r$ be the maximum of the $p_{i}, q_{i}, i=1,2, \ldots, n$. Then

(A) If $r>1$ there exists $c>0$ depending on $r$ and $\epsilon_{i j}, \epsilon_{i j}^{\prime}, i=1,2$, $\ldots, n$, such that $\left|h_{i}(t)\left[\rho_{i}(t)\right]^{-1}\right| \leq c, i=1,2, \ldots, n$, implies that the solutions of (1) exist in $[0, \infty)$ and satisfy the condition $x_{i}(t)=h_{i}(t)+a_{i}(t) \rho_{i}(t)$ where $a_{i}(t)$ is bounded. If, instead of condition $\left(\mathrm{H}_{6}\right),(1)$ satisfies $\left(\mathrm{H}_{6}^{\prime}\right)$ then $\lim _{t \rightarrow \infty} a_{i}(t)=a_{i}$. Furthermore if $\lim _{t \rightarrow \infty} h_{i}(t)\left[\rho_{i}(t)\right]^{-1}=h_{i}$ constant, then $\lim _{t \rightarrow \infty}\left(x_{i}(t) / \rho_{i}(t)\right)=b_{i}$ constant.

(B) If $r \leq 1, c$ can be chosen arbitrarily.

\section{Proof.}

$$
\begin{aligned}
\frac{\left|x_{i}(t)\right|}{\left|\rho_{i}(t)\right|} \leq & K_{i}+\int_{0}^{t} \sum_{r=1}^{n} \frac{\left|q_{i r}(t, s)\right|\left|\rho_{r}(s)\right|}{\left|\rho_{i}(t)\right|} \sum_{j=1}^{n} \epsilon_{r j}(s)\left|\rho_{j}(s)\right|^{p}\left|\rho_{r}^{-1}(s)\right| \frac{\left|x_{j}(s)\right|^{p}}{\left|\rho_{j}(s)\right|^{p}} d s \\
& +\int_{0}^{t} \sum_{r=1}^{n} \frac{\left|q_{i r}(t, s)\right|\left|\rho_{r}(s)\right|}{\left|\rho_{i}(t)\right|} \sum_{j=1}^{n} \epsilon_{r j}^{\prime}(s)\left|\rho_{j}\left(u_{j}(s)\right)\right|^{q}\left|\rho_{r}^{-1}(s)\right| \frac{\left|x_{j}(s)\right|^{q}}{\left|\rho_{j}\left(u_{j}(s)\right)\right|^{q_{j}}} d s \\
& +\int_{0}^{t} \sum_{j=1}^{n} \frac{\left|q_{i j}(t, s)\right|\left|\rho_{j}(s) \rho_{j}(s)\right|^{-1}}{\left|\rho_{i}(t)\right|}\left|g_{j}(s)\right| d s
\end{aligned}
$$




$$
\begin{aligned}
& \leq K_{i}+\int_{0}^{t} \sum_{r=1}^{n} C_{r} \sum_{j=1}^{n} \epsilon_{r j}(s)\left|\rho_{j}(s)\right|^{p_{j}} \rho_{r}(s)-1 \frac{\left|x_{j}(s)\right|^{p_{j}}}{\left|\rho_{j}(s)\right|^{p_{j}}} d s \\
& +\int_{0}^{t} \sum_{r=1}^{n} C_{r} \sum_{j=1}^{n} \epsilon_{r j}^{\prime}(s)\left|\rho_{j}\left(u_{j}(s)\right)\right|^{q}{ }_{j}\left|\rho_{r}(s)\right|^{-1} \frac{\left|x_{j}(s)\right|^{q}}{\left|\rho_{j}\left(u_{j}(s)\right)\right|^{q}} d s \\
& +\int_{0}^{t} \sum_{r=1}^{n} C_{j}\left|g_{j}(s) \rho_{j}(s)^{-1}\right| d s \\
& \leq K_{i}+K \int_{0}^{t}\left(\sum_{r, j=1}^{n} \epsilon_{r j}(s)\left|\rho_{j}(s)\right|^{p_{j}} \rho_{r}(s)^{-1} \sum_{i=1}^{n} \frac{\left|x_{i}(s)\right|^{p_{i}}}{\left|\rho_{i}(s)\right|^{p_{i}}}\right) d s \\
& +K \int_{0}^{t}\left(\sum_{r, j=1}^{n} \epsilon_{r j}^{\prime}(s)\left[\rho_{j}\left(u_{j}(s)\right)\right]^{q_{j}} \rho_{r}(s)^{-1} \sum_{i=1}^{n} \frac{\left|x_{i}(s)\right|^{q_{i}}}{\left|\rho_{i}\left(u_{i}(s)\right)\right|^{q_{i}}}\right) d s \\
& \left.=K_{i}+K \int_{0}^{t} d s\right)\left(\sum_{k=1}^{n} \frac{\left|x_{k}(s)\right|^{p_{k}}}{\left|\rho_{k}(s)\right|^{p_{k}}}\right) d s \\
& +K \int_{0}^{t} b(s)\left(\sum_{k=1}^{n} \frac{\left|x_{k}(s)\right|^{q} k}{\left|\rho_{k}\left(u_{k}\right)\right|^{q_{k}}}\right) d s \\
& =F_{i}(t) \text {. }
\end{aligned}
$$

Since $F_{i}(t)$ is monotone nondecreasing and $u_{i}(t) \leq t$ for every $i$ we have

$$
\left|x_{i}\left(u_{i}(t)\right)\right| /\left|\rho_{i}\left(u_{i}(t)\right)\right| \leq F_{i}\left(u_{i}(t)\right) \leq F_{i}(t), \quad i=1,2, \ldots, n,
$$

but

$$
\begin{aligned}
F_{i}^{\prime}(t) & =K a(t)\left(\sum_{k=1}^{n} \frac{\left|x_{k}(t)\right|^{p_{k}}}{\left|\rho_{k}(t)\right|^{p_{k}}}\right)+K b(t)\left(\sum_{k=1}^{n} \frac{\left|x_{k}\left(u_{k}(t)\right)\right|^{q_{k}}}{\left|\rho_{k}\left(u_{k}(t)\right)\right|^{q_{k}}}\right) \\
& \leq K a(t) \sum_{k=1}^{n} F_{k}(t)^{p_{k}}+K b(t) \sum_{k=1}^{n} F_{k}(t)^{q_{k}} .
\end{aligned}
$$

If for every $k, F_{k}(t) \leq 1,\left|x_{k}(t)\right| /\left|\rho_{k}(t)\right| \leq F_{k}(t)$ are bounded, and that is what we ultimately want to prove, if for some $k, F_{k}(t)>1$ by [2, Lemma 3],

$$
\sum_{k=1}^{n} F_{k}(t)^{p_{k}} \leq n K\left(\sum_{k=1}^{n} F_{k}(t)\right)^{p}, \quad \sum_{k=1}^{n} F_{k}(t)^{q} \leq n\left(\sum_{k=1}^{n} F_{k}(t)\right)^{q},
$$

$p=\max _{k} p_{k}, q=\max _{k} q_{k}$. If $r=\max (p, q)$ then 


$$
F_{i}^{\prime}(t) \leq n K(a(t)+b(t)) F(t)^{r}
$$

where $F(t)=\sum_{k=1}^{n} F_{k}(t)$ and $F^{\prime}(t) \leq n^{2} K(a(t)+b(t)) F(t)^{r}$.

$\sum_{i=1}^{n}\left(\left|x_{i}(t)\right| /\left|\rho_{i}(t)\right|\right) \leq F(t) \leq z(t)$ where $z(t)$ is the maximal solution of the differential equation

$$
\dot{z}=n^{2} K(a,(t)+b(t)) z(t)^{r}
$$

with the same reasoning made in [2], it is easy to show that the solutions of equation (2) are bounded when $r>1$ if $|z(0)| \leq C$ for $C$ small enough and are globally bounded if $r \leq 1$.

Thus in the conditions of hypothesis $\left(\mathrm{H}_{6}\right), x_{i}(t)=h_{i}(t)+\rho_{i}(t) a_{i}(t)$ where

$$
a_{i}(t)=\int_{0}^{t} \sum_{r=1}^{n} \frac{q_{i r}(t, s)}{\rho_{i}(t)} f_{r}(s, x(s), x(u(s))) d s+\int_{0}^{t} \sum_{j=1}^{n} \frac{q_{i j}(t, s)}{\rho_{i}(t)} g_{r}(s) d s
$$

is bounded and in the conditions of hypothesis $\left(\mathrm{H}_{6}^{\prime}\right)$ by [2, Lemma 1], $\lim _{t \rightarrow \infty} a_{i}(t)=$ constant.

Remark 1. The results above are also true for the more general integral equation

$$
x(t)=h(t)+\int_{0}^{t} F(t, s, x(s), x(u(s))) d s
$$

where $F$ is continuous in $t$ and $x$ and $|F|$ is locally Lebesgue integrable and satisfies the hypothesis

$$
\begin{aligned}
\mid F_{i}(t, s, x(s) & , x(u(s)))\left.|| \rho_{i}(t)\right|^{-1} \\
& \leq \sum_{j=1}^{n} g_{i j}(s)\left|x_{j}\right|^{p}+\sum_{j=1}^{n} g_{i j}^{\prime}(s)\left|x_{j}\left(u_{j}(s)\right)\right|^{q},
\end{aligned}
$$

$|x|<H<\infty$ where $g_{i j} \geq 0, g_{i j}^{\prime}>0, p_{j} \geq 0, q_{j}>0, i, j=1,2, \ldots, n$, and

$$
\int^{\infty} g_{i j}(t)\left|\rho_{j}(t)\right|^{p_{j}} d t<\infty, \quad \int^{\infty} g_{i j}(t)\left|\rho_{j}\left(u_{j}(t)\right)\right|^{q} d t<\infty
$$

or

$\left(\mathrm{H}_{7}^{\prime}\right)\left(\mathrm{H}_{7}\right)$ is satisfied and $\lim _{t \rightarrow \infty} F_{i}(t, s, x(s), x(u(s)))\left[\rho_{i}(t)\right]^{-1}$ exists and is finite for almost all values of $s$.

Then conditions (A) and (B) of Theorem 1 are satisfied for equation (3). Still more generally let $\rho=\left(\rho_{i}(t)\right)$ be a diagonal matrix, $\left|\rho_{i}(t)\right|>0, i=1,2$, $\ldots, n$, chosen in such a way that $\left|\rho(t)^{-1} h(t)\right|<K$. Suppose that

$$
\left|\rho(t)^{-1} F(t, s, x(s), x(u(s)))\right|<\omega\left(t, s,\left|\rho(s)^{-1} x(s)\right|,\left|\rho(u(s))^{-1} x(u(s))\right|\right)
$$

where $\omega\left(t, s, r_{1}, r_{2}\right)$ is monotone in $r_{j}$ for $i \neq j$ for each $\left(t, s, r_{i}\right)$. Then if the solutions of the integral equation

$$
y(t)=K+\int_{0}^{t} \omega(t, s, y(s), y(u(s))) d s
$$

are bounded, the solutions of (3) satisfy $x(t)=h(t)+\rho(t) a(t)$ with $a(t)$ bounded. If in addition 


$$
\lim _{t \rightarrow \infty} \rho(t)^{-1} F(t, s, x(s), x(u(s)))
$$

exists and is finite for almost all values of $s$ then $\lim _{t \rightarrow \infty} d(t)=a$ constant.

Remark 2. Theorem 1 is quite general to include several results on the asymptotic behavior and stability of Volterra integral equations and functional differential equations; for example, if $\rho_{i}(t)=k \cdot e^{-a t}, \alpha \geq 0$, for every $i$, $|h(t)|<k \cdot e^{-a t}$ and if $\left|q_{i j}(t, s)\right|<k \cdot e^{-a(t-s)}$ then $\left(\mathrm{H}_{6}\right)$ is satisfied and if $\left(\mathrm{H}_{4}\right)$ is satisfied with $\int^{\infty} \epsilon_{i j}(t) \cdot e^{-\alpha\left(q_{j}-1\right) t} d t<\infty$ and $\int^{\infty} \epsilon_{i j}^{\prime}(t)^{-\alpha\left(q_{j}-1\right) t} d t<\infty$ then the solutions of (1) in a neighborhood of the origin are uniformly asymptotically stable if $\alpha>0$ and uniformly stable if $\alpha=0$; in particular, the representation of the solution of the functional differential equation

$$
\begin{gathered}
\dot{x}=L\left(t, x_{t}\right)+f(t, x(t), x(u(t))), \quad x_{t}(\theta)=x(t+\theta), \\
\Omega \subset R \times C\left([-r, 0], E^{n}\right), \quad L: \Omega \rightarrow E^{n},
\end{gathered}
$$

is linear, is given by

$$
x(t)=T(t) \phi+\int_{0}^{t} U(t, s) f(s, x(s), x(u(s))) d s, \quad T: C \rightarrow C,
$$

and if the solutions of

$$
\dot{y}=L\left(t, y_{t}\right)
$$

are uniformly asymptotically stable, then $\|T(t)\| \leq k \cdot e^{-\alpha t}, \alpha>0$, and $|U(t, s)| \leq k \cdot e^{-\alpha(t-s)}$ and, by the reasoning above, if $f$ satisfies $\left(\mathrm{H}_{6}\right)$ then the solutions of (4) with $x(0)$ small enough are uniformly asymptotically stable; in particular, if the solutions of (5) are uniformly stable, $\|T(t) \phi\|$ is bounded and $|U(t, s)|$ is bounded, and if $f$ satisfies $\left(\mathrm{H}_{6}\right)$ with $\rho_{i}(t)=k$ constant, then the solutions of (4) are uniformly stable if $x(0)$ is small enough.

Consider now the systems

$$
\begin{aligned}
\dot{x}=A(t) x+f(t, & x(t), x(u(t)))+g(t), \\
\cdot & =A(t) y
\end{aligned}
$$

satisfying the conditions:

$$
\begin{aligned}
&\left|f_{i}(t, x, y)\right| \leq \sum_{i=1}^{n} \epsilon_{i j}(t)\left|x_{j}\right|^{p}{ }_{j}+\sum_{j=1}^{n} \epsilon_{i j}^{\prime}(t)\left|y_{j}\right|^{q}, \\
& \epsilon_{i j} \geq 0, \quad \epsilon_{i j}^{\prime} \geq 0, \quad p_{j}, q_{j}>0, \quad i, j=1,2, \ldots, n, \\
& \quad|x|<H, \quad|y|<H, \quad H \leq \infty,
\end{aligned}
$$

$$
\begin{gathered}
\left.\mathrm{H}_{4}^{\prime}\right) \quad \int_{i j}^{\infty} \epsilon_{i j}(t)|\operatorname{det} \rho(t)| \exp \left[-\int_{T_{0}}^{t} T_{r} A(s) d s\right]\left|\rho_{j}(t)\right|^{p}\left|\rho_{i}(t)\right|^{-1} d t<\infty, \\
i, j=1,2, \ldots, n, \quad\left|\rho_{i}(t)\right|>0, \\
\int^{\infty} \epsilon_{i j}^{\prime}(t)|\operatorname{det} \rho(t)| \exp \left[-\int_{T_{0}}^{t} T_{r} A(s) d s\right]\left|\rho_{j}\left(u_{j}\right)\right|^{q}\left|\rho_{i}(t)\right|^{-1} d t<\infty,
\end{gathered}
$$




$$
\left(\mathrm{H}_{s}^{\prime}\right) \quad \int^{\infty}\left|g_{i}(t)\right||\operatorname{det} \rho(t)| \exp \left[-\int_{T_{0}}^{t} T_{r} A(s) d s\right]\left|\rho_{i}(t)\right|^{-1} d t<\infty \text {. }
$$

The following theorem generalizes Theorem 1 of Ladas [5], Theorem 1 of Marušiak [6] for delay equations and several theorems on the asymptotic behavior of ordinary differential equations, in particular Theorem 2.1 of Hallam [2], Theorem 1 of Waltman [9], Theorem 2.1 of Izé [3], and was proved in [4]

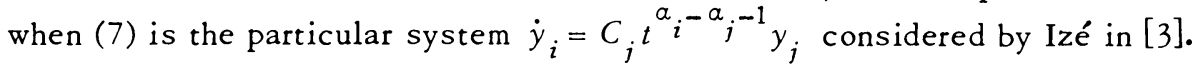

Theorem 2. Suppose there exists a diagonal matrix $\rho(t)=\left(\rho_{i}(t)\right),\left|\rho_{i}(t)\right|$ $>0, i=1,2, \ldots, n$, such that for every solution $y(t)$ of $(7), y_{i}(t)=$ $\left(a_{i}+o(1)\right) \rho_{i}(t)$. Let $f$ and $g$ satisfy $\left(\mathrm{H}_{4}^{\prime}\right)$ and $\left(\mathrm{H}_{5}^{\prime}\right)$ and let $r=\max _{i}\left(p_{i}, q_{i}\right)$. Then: (A) If $r>1$, for every solution $y(t)=\left(y_{1}, y_{2}, \ldots, y_{n}\right)$ of (7) with $\left|y\left(t_{0}\right)\right|$ small enough there exists a solution $x(t)$ of $(6)$ with $x\left(t_{0}\right)=z\left(t_{0}\right)$ such that $x_{i}(t)=z_{i}(t)+\left(a_{i}+o(1)\right)$. (B) If $r \leq 1$ then for every solution $y(t)$ of (7) there exists a solution $y(t)$ of $(6)$ with $y\left(t_{0}\right)=z\left(t_{0}\right)$ such that $y_{i}(t)=$ $z_{i}(t)+\left(a_{i}+o(1)\right) \rho_{i}(t), i=1,2, \ldots, n$, and conversely for every solution $x(t)$ of (6) there exists a solution $y(t)$ of (7) with $y\left(t_{0}\right)=x\left(t_{0}\right)$ such that $x_{i}(t)=y_{i}(t)+\left(a_{i}+o(1)\right) \rho_{i}(t), i=1,2, \ldots, n$.

In particular, if there exists a solution of (7) such that $x_{i}(t)=z_{i}(t)+$ $\left(a_{i}+o(1)\right) \rho_{i}(t)$ with $\left(a_{1}, a_{2}, \ldots, a_{n}\right) \neq 0$ then there exists at least a solution $x(t)$ of (6) such that $\lim _{t \rightarrow \infty}\left(x_{i}(t) / \rho_{i}(t)\right)=b_{i}, i=1,2, \ldots, n$, with $\left(b_{1}, b_{2}, \ldots, b_{n}\right) \neq 0$.

Proof. A general solution of (6) can be written in the form

$$
x(t)=y(t)+\int_{t_{0}}^{t} U(t) U^{-1}(s) f(s, x(s), x(u(s))) d s+\int_{0}^{t} U(t) U^{-1}(s) g(s) d s .
$$

By $\left[3\right.$, Lemma 3, p. 8] $U(t) \cdot U^{-1}(s)=C_{i r}(t, s)$ where

$$
c_{i r}(t, s)=\frac{\operatorname{det} C_{i r}^{\prime}(t, s)}{\operatorname{det} U(s)}
$$

and $\left(C_{i r}^{\prime}(t, s)\right)$ is the matrix which we obtain by substitution of the row of order $i$ of matrix $U(t)$ in the row of order $r$ in the matrix $U(s)$. Then if $U(t)=$ $\left(y_{i l}(t)\right), i, l=1,2, \ldots, n$,

$$
\begin{aligned}
C_{i r}^{\prime}(t, s) & =\sum_{l=1}^{n} y_{i l}(t) \cdot G_{r l}(s) \\
& =\sum_{l=1}^{n} y_{i l}(t) \rho_{i}(t) \rho_{i}(t)^{-1} \rho_{r}(s)^{-1} \operatorname{det} \rho(s) U_{r l}(s) \\
& =\rho_{i}(t) \rho_{r}(s)^{-1} \operatorname{det} \rho(s) \sum_{l=1}^{n} D_{r l}(t, s)
\end{aligned}
$$

where $D_{r l}(t, s)$ is a bounded function and $\lim _{t \rightarrow \infty} D_{r l}(t, s)$ exists, since $\lim _{t \rightarrow \infty} y_{i l}(t)\left[\rho_{i}(t)\right]^{-1}$ exists by hypothesis. 
By the Jacobi-Liouville formula we have

$$
\operatorname{det} U(t)=k \exp \left(-\int_{T_{0}}^{t} T_{r}(A(s)) d s\right), \quad T_{0} \geq t_{0},
$$

and

$$
C_{i r}(t, s)=\frac{1}{k}\left[\exp -\int_{T_{0}}^{s} T_{r}(A(v)) d v\right] \rho_{i}(t) \rho_{r}^{-1}(s) \operatorname{det} \rho(s) \sum_{l=1}^{n} D_{r l}(t, s),
$$

then

$$
\begin{aligned}
\frac{x_{i}(t)}{\rho_{i}(t)}= & \frac{y_{i}(t)}{\rho_{i}(t)} \\
& +\frac{1}{K} \int_{t_{0}}^{t} \operatorname{det} \rho(s)\left[\exp -\int_{T_{0}}^{s} T_{r}(A(v)) d v\right] \sum_{r=1}^{n} \rho_{r}^{-1}(s) \sum_{l=1}^{n} D_{r l}(t, s) \\
& +f_{r}(s, x(s), x(u(s))) d s \\
& +\frac{1}{K} \int_{t_{0}}^{t} \operatorname{det} \rho(s)\left[\exp -\int_{T_{0}}^{s} T_{r}(A(v)) d v\right] \sum_{j=1}^{n} \rho_{j}^{-1}(s) \sum_{l=1}^{n} D_{j l}(t, s) g_{j}(s)
\end{aligned}
$$

by substitution of $f_{r}\left(s, x(s), x(u(s))\right.$ given by hypothes is $\left(\mathrm{H}_{6}^{\prime}\right)$; the reasoning is the same used in Theorem 1 and we conclude that $x_{i}(t)=y_{i}(t)+$ $\left(a_{i}+o(1)\right) \rho_{i}(t)$.

We have only to prove now that there exists a solution $x(t)$ for which $\lim _{t \rightarrow \infty}\left(x_{i}(t) / \rho_{i}(t)\right)=b_{i}$ with $b_{i} \neq 0$ for at least one $i$.

By hypothesis there exists at least a solution $y(t)$ of (7) for which $\lim _{t \rightarrow \infty}\left(y_{i}(t) / \rho_{i}(t)\right)=a_{i}$ with $a_{i} \neq 0$ for some $i$.

From the proof of Theorem 2 and [2, Lemma 1], it is not difficult to see that

$$
\begin{gathered}
\lim _{t \rightarrow \infty} \frac{1}{\rho_{i}(t)} \int_{t_{0}}^{t} \sum_{r=1}^{n} C_{i r}(t, s) f_{r}(s, x(s), x(u(s))) d s \\
+\frac{1}{\rho_{i}(t)} \int_{t_{0}}^{t} \sum_{j=1}^{n} C_{i j}(t, s) h_{j}(s) d s=A_{i}
\end{gathered}
$$

with $\left|A_{i}\right|<a_{i}$ if $t_{0}$ is large enough, then

$$
\lim _{t \rightarrow \infty}\left(x_{i}(t) / \rho_{i}(t)\right)=a_{i}+A_{i} \neq 0 .
$$

To prove that, if $r \leq 1$, for every solution $x(t)$ of (6) there exists a solution $y(t)$ of (7) such that $x_{i}(t)=y_{i}(t)+\left(a_{i}+o(1)\right) \rho_{i}(t)$, since every solution of (6) has this form, we have only to write $y(t)$ given by the integral equation

$$
y(t)=x(t)-\int_{t_{0}}^{t} U(t) U^{-1}(s) f(s, x(s), x(u(s))) d s-\int_{t_{0}}^{t} U(t) U^{-1}(s) g(s) d s
$$

As a simple application of Theorem 2 consider the equation 


$$
\begin{aligned}
x^{(n)}+f\left(t, x(t), x^{(1)}(t) \cdots x^{(n-1)}(t), x\left(u_{1}(t)\right),\right. & x^{(1)}\left(u_{2}(t)\right) \\
& \left.\cdots x^{(n-1)}\left(u_{n}(t)\right)\right)=0 .
\end{aligned}
$$

As every solution of $y^{(n)}=0$ has the form

$$
y^{(i)}(t)=C_{0 i}+C_{1 i} t+\cdots+C_{n-i, i} t^{n-i},
$$

$i=0,1, \ldots, n-1$, every solution of (8) has the form

$$
\begin{aligned}
x^{(i)}(t)=C_{0 i}+C_{1 i}+\cdots+C_{n-i, i} t^{n-i}+\left(a_{i}+o(1)\right) t^{n-i} & \\
\rho_{i}(t) & =t^{n-i}, \quad i=0,1, \ldots, n-1 .
\end{aligned}
$$

In particular there is a nonoscillatory solution of (8) satisfying $\lim _{t \rightarrow \infty}\left(x^{(n-i)}(t) / t^{n-i}\right)=C_{n-i, i} \neq 0$ for every $i$, and this result generalizes Theorem 1 of [5] and Theorem 1 of [6]. Particularly if (7) is the general singular system considered in [3] then equation (6) which in this case contains (8) will have a solution satisfying $\lim _{t \rightarrow \infty}\left(x_{i}(t) / t^{\alpha i}\right)=b_{i}$.

Example. The differential equation

$$
s^{\prime}(t)=-\beta(t) s(t)[2 \gamma(t)+s(t-14)-s(t-12)]+\gamma(t)
$$

is a delay differential equation, studied by J. A. Yorke [10] which describes how the measles spreads through a population as a function of time, where $s(t)$ is the number of susceptible individuals, $\beta(t)$ is a proportionality constant that is seasonally dependent, having a one-year period, and $\gamma(t)$ is the rate at which susceptible individuals enter the population (through net immigration or birth). If $I(t)$ is the number of infectious individuals,

$$
I(t)=\int_{t-14}^{t-12} \beta(x) s(x) I(x) d x=\int_{t-14}^{t-12}\left[\gamma(x)-s^{\prime}(x)\right] d x .
$$

Equation (9) can be written in the form

$$
s^{\prime}(t)=-2 \beta(t) \gamma(t) s(t)-\beta(t)[s(t-14)-s(t-12)] s(t)+\gamma(t) .
$$

Then if $\rho(t)=\exp -2 \int_{0}^{t} \beta(t) \gamma(t) d t, u_{1}(t)=t-14, u_{2}(t)=t-12$,

$$
\begin{aligned}
|f(t, x, y)| & =\left|-\beta(t)[s(t-14)-s(t-12)]_{s}(t)\right| \\
& \leq \mid \beta(t)\left[|s(t)|^{2}+1 / 2|s(t-14)|^{2}+1 / 2|s(t-12)|^{2}\right],
\end{aligned}
$$

$g(t)=\gamma(t)$ under certain circumstances, it is possible to have hypotheses $\left(\mathrm{H}_{4}^{\prime}\right)$ and $\left(\mathrm{H}_{5}^{\prime}\right)$ satisfied, that is:

$$
\begin{gathered}
\int^{\infty} \beta(t) \exp \left[-2 \int_{0}^{t} \beta(\tau) \gamma(\tau) d \tau\right] d t<\infty, \\
\int^{\infty} \beta(t) \exp \left[-2 \int_{0}^{t-14} \beta(\tau) \gamma(\tau) d \tau+2 \int_{0}^{t} \beta(\tau) \gamma(\tau) d \tau\right] d t<\infty, \\
\int^{\infty} \beta(t) \exp \left[-2 \int_{0}^{t-12} \beta(\tau) \gamma(\tau) d \tau+2 \int_{0}^{t} \beta(\tau) \gamma(\tau) d \tau\right] d t<\infty,
\end{gathered}
$$




$$
\int^{\infty} \gamma(t) \exp \left[2 \int_{0}^{t} \beta(\tau) \gamma(\tau) d \tau\right] d t<\infty .
$$

Under these conditions by Theorem 2 there is a solution for $s(0)$ small enough such that

$$
s(t)=\exp \left[-2 \int_{0}^{t} \gamma(\tau) \beta(\tau) d \tau\right][a+o(1)] .
$$

\section{REFERENCES}

1. T. G. Hallam, Asymptotic behavior of the solutions of an nth order nonhomogeneous ordinary differential equation, Trans. Amer. Math. Soc. 122 (1966), 177-194. MR $32 \# 6000$.

2. A. F. Izé, On an asymptotic property of a Volterra integral equation, Proc. Amer. Math. Soc. 28 (1971), 93-99. MR $43 \# 836$.

3. - A symptotic integration of a nonhomogeneous singular linear system of ordinary differential equation, J. Differential Equations 8 (1970), 1-15. MR 41 \#3898.

4. A. A. Freiria, Sobre comportamento assintótico e existência de soluções não oscilatórias de uma classe de sistema de equações diferencias com retardamento, São Carlos, 1972.

5. G. Ladas, Oscillation and asymptotic behavior of solutions of differential equations with retarded argument, J. Differential Equations 10 (1971), 281-290. MR $45 \# 681$.

6. P. Marušiak, Note on the Ladas' paper on oscillation and asymptotic behavior of solutions of differential equations with retarded argument, J. Differential Equations 13 (1973), 150-156. 1971.

7. R. K. Miller, Nonlinear Volterra integral equations, Benjamin, New York,

8. J. A. Nohel, Some problems in nonlinear Volterra integral equations, Bull. Amer. Math. Soc. 68 (1962), 323-329. MR $26 \# 2838$.

9. P. Waltman, On the asymptotic behavior of solutions of a nonlinear equation, Proc. Amer. Math. Soc. 15 (1964), 918-923. MR 31 \#445.

10. J. A. Yorke, Selected topics in differential delay equations, Japan-U.S.A. Seminar on Ordinary Differential and Functional Equations, Lecture Notes in Math., vol. 143, Springer-Verlag, Berlin and New York, 1971, pp. 16-28.

INSTITUTO DE CIÊNCIAS MATEMÁTICAS, DE SAO CARLOS, UNIVERSIDADE DE SÃO PAULO, SÃO CARLOS, BRASIL L. AND 02912

DEPARTMENT OF MATHEMATICS, BROWN UNIVERSITY, PROVIDENCE, RHODE IS-

FACULDADE DE FILOSOFIA, CIÊNCIAS E LETRAS DE RIBEIRÃO PRETO, RIBEIRÃO PRETO, BRASIL 